\title{
A COMPARATIVE STUDY OF INTRATHECAL DEXMEDETOMIDINE AND MIDAZOLAM AS AN ADJUVANT TO BUPIVACAINE FOR TOTAL ABDOMINAL HYSTERECTOMY
}

\author{
C. N. Vinod ${ }^{1}$, H. S. Suraj ${ }^{2}$
}

${ }_{1}$ Associate Professor, Department of Anaesthesia, KIMS Hospital, Bangalore, Karnataka, India.

${ }^{2}$ Assistant Professor, Department of Anaesthesia, KIMS Hospital, Bangalore, Karnataka, India.

ABSTRACT
BACKGROUND
Dexmedetomidine, a highly selective $\alpha 2$ adrenergic agonist and Midazolam, a benzodiazepine derivative both modulate spinal
analgesia by different mechanisms. We compared Dexmedetomidine and Midazolam as an adjuvant to hyperbaric Bupivacaine in
subarachnoid blockade to evaluate the onset and duration of motor and sensory block, post-operative analgesia, hemodynamic
changes and adverse effects.

\section{MATERIALS AND METHODS}

In this randomized controlled trial, sixty female patients aged 18 - 65 years of ASA grade 1 and 2, randomly allocated into two groups (30 in each group), posted for total abdominal hysterectomy, were studied. Group D received 12.5 mg of hyperbaric Bupivacaine plus Dexmedetomidine $(10 \mu \mathrm{g})$ in $1 \mathrm{ml}$ of normal saline. Group M received $12.5 \mathrm{mg}$ hyperbaric Bupivacaine plus Midazolam $(2.5 \mathrm{mg}$ ) in $1 \mathrm{ml}$ of normal saline. The two groups were compared with respect to onset of sensory and motor block, regression time of sensory and motor block, rescue analgesia, hemodynamic data and adverse effects. Sample size was taken for convenience. Statistical Package for Social Science (SPSS 18.0 evaluation version) was used for the analysis to obtain the data and Microsoft Word, Excel have been used to generate graphs, tables, etc. Results on continuous measurement are presented on Mean \pm SD and continuous data is analysed. Significance is assessed at $5 \%$ level of significance.

\section{RESULTS}

Group D patients showed a significantly prolonged sensory and motor block than Group M patients. The sensory regression time to S1 was (324.67 $\pm 27.26 \mathrm{~min})$ in Group D and (254.00 $\pm 20.44 \mathrm{~min})$ in Group M. The time of motor block regression to reach Bromage 0 was (314.33 $\pm 23.44 \mathrm{~min})$ in Group D and (212.33 $\pm 11.35 \mathrm{~min})$ in Group M. Rescue analgesic time was significantly prolonged in Group D (419.33 $\pm 21.80 \mathrm{~min})$ as compared to Group M (271.33 $\pm 30.14 \mathrm{~min})$.

\section{CONCLUSION}

Dexmedetomidine (10 mcg) as an adjuvant to Bupivacaine in subarachnoid blockade is associated with longer sensory, motor block and longer duration of analgesia in comparison to Midazolam (2.5 mg) with a comparable incidence of side effects.

\section{KEY WORDS}

Spinal Anaesthesia, Bupivacaine, Dexmedetomidine, Midazolam.

HOW TO CITE THIS ARTICLE: Vinod CN, Suraj HS. A comparative study of intrathecal dexmedetomidine and midazolam as an adjuvant to bupivacaine for total abdominal hysterectomy. J. Evolution Med. Dent. Sci. 2019;8(03):191-194, DOI: $10.14260 /$ jemds $/ 2019 / 42$

\section{BACKGROUND}

Spinal Anaesthesia is one of the most commonly used techniques for lower abdominal surgery as it is very economical and easy to administer with the advantage of providing surgical anaesthesia. However, post-operative pain management is a problem because spinal anaesthesia using local anaesthetics alone is associated with relatively short duration of action and thus early intervention is required in the post-operative period.

Different adjuvants such as Opioids, magnesium sulphate, clonidine, and others have been used to prolong the effect of spinal anaesthesia. ${ }^{1,2}$

'Financial or Other Competing Interest': None.

Submission 06-12-2018, Peer Review 08-01-2019,

Acceptance 14-01-2019, Published 21-01-2019.

Corresponding Author:

C. N. Vinod,

Associate Professor, Department of Anaesthesia,

KIMS Hospital, K. R. Road,

V. V. Puram, Bangalore-560004,

Karnataka, India.

E-mail:drvinodcn@yahoo.co.in

DOI: $10.14260 /$ jemds/2019/42

\section{(c) (i) $($ ) (}

Dexmedetomidine, a highly selective $\alpha 2$ adrenergic agonist, when used as an adjuvant to spinal Bupivacaine provides a good quality of analgesia with fewer side effects. . $^{3,4}$

Midazolam, a benzodiazepine derivative has been used for potentiating the analgesic effect of local anaesthetic induced neural blockade.5,6 This study was designed to assess the effect of Dexmedetomidine, and Midazolam added to hyperbaric Bupivacaine intrathecally on onset and duration of sensory and motor block, duration of analgesia and any side effects in patients undergoing total abdominal hysterectomy.

\section{MATERIALS AND METHODS}

After obtaining approval from the hospital ethical committee along with written and informed consent, 60 adult female patients belonging to ASA class I and II aged 18-65 years posted for total abdominal hysterectomy under subarachnoid blockade were enrolled in this Randomized controlled trial.

Sample Size taken for Convenience

This study was carried out in the Department of anaesthesia at Kempegowda Institute of Medical Science and Hospital, Bangalore from September 2016 to August 2017. A 
computer-generated random allocation sequence was obtained, and the patients were allocated based on that list. All patients were randomly divided into two groups with 30 patients in each group. Patients with history of Ischemic heart disease, hypertension, allergy to the study drug, dysrhythmias or any contraindication for spinal anaesthesia and failure of spinal block were excluded from the study.

All patients advised fasting for 6 hours and received Pantoprazole $40 \mathrm{mg}$ the night before surgery and were familiarized with visual analogue scale (VAS). ${ }^{7}$

On arrival to the operation room, pulse oximetry, noninvasive blood pressure and electro cardiogram were monitored. IV Line was secured and infusion of $500 \mathrm{ml}$ of lactated Ringers solution was given. Under all aseptic precautions patients back painted and draped in sitting position. At L3-L4 intervertebral space, using 26G Quincke spinal needle lumbar puncture was done.

\section{Group D (30 Patients)}

Received $12.5 \mathrm{mg}$ hyperbaric Bupivacaine $(2.5 \mathrm{ml})$ plus Dexmedetomidine $(10 \mu \mathrm{g})$ in $1 \mathrm{ml}$ of normal saline.

\section{Group M (30 Patients)}

Received $12.5 \mathrm{mg}$ hyperbaric Bupivacaine plus Midazolam $(2.5 \mathrm{mg})$ in $1 \mathrm{ml}$ of normal saline.

After intrathecal injection, Patients were positioned in supine position and oxygen $5 \mathrm{l} / \mathrm{min}$ was given through a face mask. The anaesthesiologist performing the block was blinded to the study drug and recorded the intraoperative data. The onset of sensory and motor block, highest level of sensory block, time to complete motor block recovery and duration of spinal anaesthesia were recorded. The sensory block onset time is defined as time interval between injection of drug and the absence of pain at T10 dermatome assessed by sterile pinprick every 2 min till T10. On achieving T7 sensory blockade, procedure was started. Pin prick test was done every $10 \mathrm{~min}$. until the point of 2 segment regression of the block was observed. Modified Bromage scale was used to assess the motor level:

- $\quad$ Grade 0: Patient able to move ankle, knee and hip.

- Grade 1: Patient able to move the knee and ankle but is unable to move the hip.

- Grade 2: Patient is, able to move the ankle but is unable to move the hip and knee

- $\quad$ Grade 3: Patient unable to move the ankle, knee and hip.

Hemodynamic data were recorded at 5, 10, 15, 20, 25, 30 min and subsequently every $30 \mathrm{~min}$.

The incidence of nausea and vomiting and sedation were recorded. Sedation was assessed by modified Ramsay sedations scale:

1. Patient agitated, anxious and restless.

2. Patient is oriented co-operative and tranquil.

3. Patient responds to verbal commands while sleeping.

4. Patient exhibits brisk response to light loud noise or glabellar tap while sleeping.

5. Patient sluggishly responses to light loud noise or glabellar tap while sleeping.

6. Patient does not respond to light glabellar tap or loud noise while sleeping.
Sensory and motor block regression time was recorded in a post anaesthesia care unit (PACU) along with the vital signs and Visual analogue scale (VAS) scores. Any patients showing VAS more than or equal to 3 was considered as rescue analgesic requirement and Inj. Diclofenac intramuscularly was given.

\section{Statistical Analysis}

Statistical Analysis was done using student's t test, Leven`s test.

Significance is assessed at $5 \%$ level of significance. $\mathrm{P}$ Value $<0.05$ was considered statistically significant. Statistical package for social science (SPSS 18.0 evaluation version) was used for the analysis to obtain the data and Microsoft word, Excel have been used to generate graphs, tables, etc. Results on continuous measurement are presented on Mean \pm SD.

\section{RESULTS}

The two groups were found to be comparable with respect to age, height, weight and ASA physical status (Table 1). The sensory and motor block characteristics and time for regression are summarized in (Table 2).

\begin{tabular}{|c|c|c|c|}
\hline \multicolumn{2}{|c|}{ Variables } & Group D & Group M \\
\hline Age (years) & Mean \pm SD & $55.17 \pm 4.35$ & $53.90 \pm 5.35$ \\
\hline Height $(\mathrm{cm})$ & Mean \pm SD & $161.8 \pm 5.25$ & $160.7 \pm 5.55$ \\
\hline Weight $(\mathrm{kg})$ & Mean \pm SD & $71.33 \pm 9.07$ & $73.73 \pm 7.98$ \\
\hline \multicolumn{4}{|c|}{ Table 1. Demography } \\
\hline
\end{tabular}

\begin{tabular}{|c|c|c|c|}
\hline Variables & $\begin{array}{c}\text { Group D } \\
\text { (Mean } \pm \text { SD) }\end{array}$ & $\begin{array}{c}\text { Group M } \\
\text { (Mean } \pm \text { SD) }\end{array}$ & p-value \\
\hline $\begin{array}{c}\text { Sensory Block } \\
\text { Onset Time (min) }\end{array}$ & $3.93 \pm 1.64$ & $4.27 \pm 1.31$ & 0.388 \\
\hline $\begin{array}{c}\text { Motor Block Onset } \\
\text { Time to Bromage -3 } \\
\text { (min) }\end{array}$ & $8.10 \pm 1.69$ & $8.70 \pm 1.70$ & 0.176 \\
\hline $\begin{array}{c}\text { Time from } \\
\text { Injection to Highest } \\
\text { Sensory Level }\end{array}$ & $10.57 \pm 1.45$ & $10.21 \pm 1.26$ & 0.316 \\
\hline $\begin{array}{c}\text { Two Segment } \\
\text { Regression Time }\end{array}$ & $134.00 \pm 16.32$ & $112.33 \pm 15.69$ & $<0.001$ \\
\hline $\begin{array}{c}\text { Sensory Regression } \\
\text { Time to S1 Segment }\end{array}$ & $324.67 \pm 27.26$ & $254.00 \pm 20.44$ & $<0.001$ \\
\hline $\begin{array}{c}\text { Motor Block } \\
\text { Regression Time to } \\
\text { Bromage 0 }\end{array}$ & $314.33 \pm 23.44$ & $212.33 \pm 11.35$ & $<0.001$ \\
\hline $\begin{array}{c}\text { Rescue Analgesia } \\
\text { Time (min) }\end{array}$ & $419.33 \pm 21.80$ & $271.33 \pm 30.14$ & $<0.001$ \\
\hline \multicolumn{3}{|c|}{ Table 2. Characteristics of Block } & \\
\hline
\end{tabular}

The onset time of block, both sensory and motor block was found to be similar in both groups. There was no statistically significant difference between the two groups with respect to highest level of block achieved. 

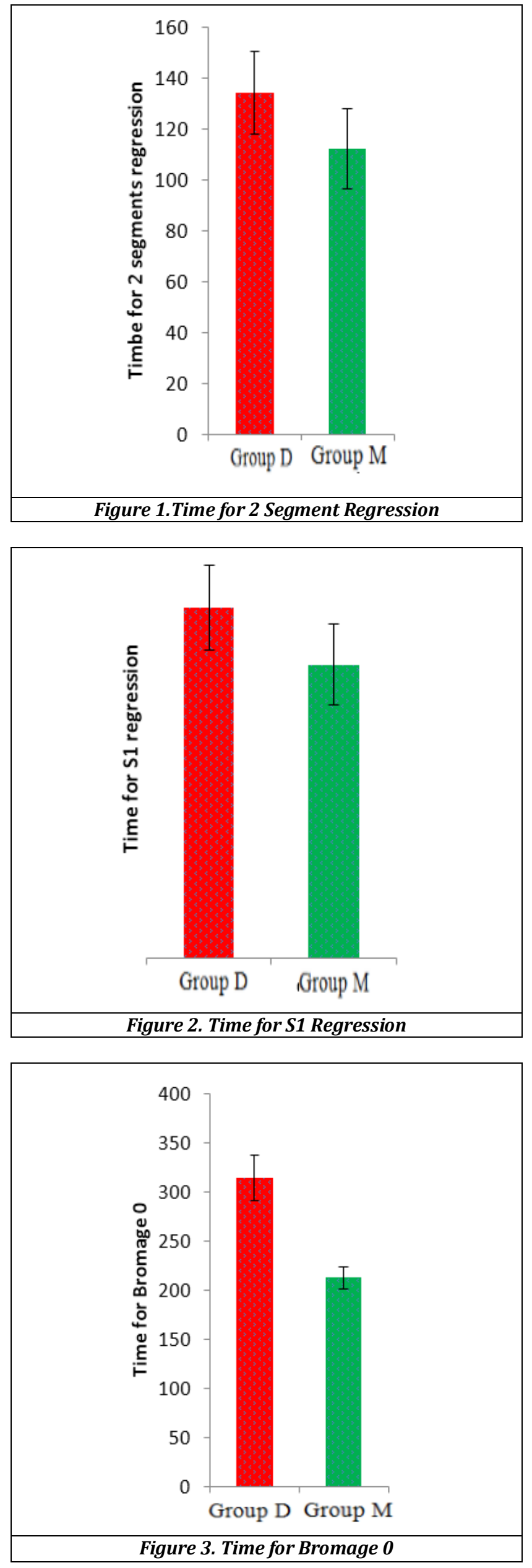

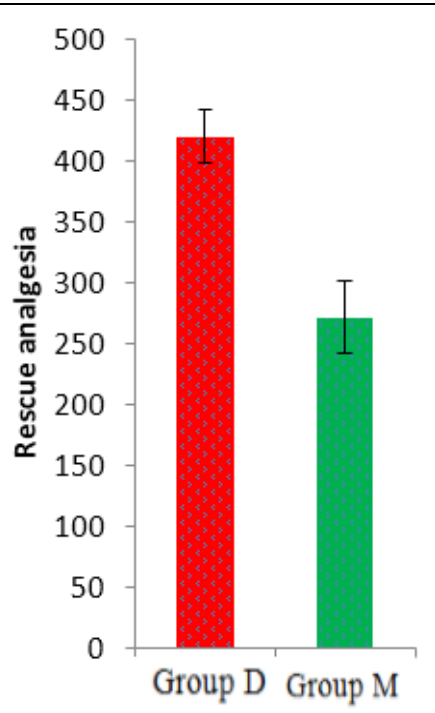

Figure 4. Rescue Analgesia

The two-segment sensory regression time and S1 segment regression time were significantly slower with Dexmedetomidine (Group D) compared to Midazolam (Group M), p-value $<0.05$. The motor block regression time to Bromage 0 was significantly slower in Group D (314.33 \pm $23.44 \mathrm{~min})$ when compared to Group M (212.33 $\pm 11.35 \mathrm{~min})$, $\mathrm{p}$-value $<0.05$. The rescue analgesic time was significantly prolonged in Group D (419.33 $\pm 21.80 \mathrm{~min})$ when compared to Group M (271.33 $\pm 30.14 \mathrm{~min})$.

There was statistically no significant difference in the mean hemodynamic data in the first hour after performing the subarachnoid block and the first hour in the PACU between the two groups. In our study hypotension and bradycardia was more in the Dexmedetomidine group than in Midazolam group, but it was not statistically significant. Degree of sedation was not statistically significant in the study group.

\section{DISCUSSION}

Various adjuvants such as clonidine, fentanyl and others have been studied to prolong the effect of spinal anaesthesia. Dexmedetomidine is an selective $\alpha 2$ adreno receptor agonist which has ten times higher affinity for $\alpha 2$ adreno receptor than Clonidine. Dexmedetomidine as an adjuvant to hyperbaric Bupivacaine in spinal anaesthesia prolongs the sensory block by inhibiting the release of C-fiber transmitters by hyper polarization of dorsal horn post synaptic neurons. ${ }^{8,9,10}$ The prolongation of motor block by $\alpha 2$ adreno receptor agonist results from binding these agonists to motor neuron in the dorsal horn of the spinal cord.11 $\alpha 2$ adreno receptor agonist given spinally have anti-nociceptive action for both somatic and visceral pain.

Midazolam, a benzodiazepine derivative mediates spinal analgesic effect by GABA receptor complex present in the dorsal horn of the spinal cord. ${ }^{12}$ Intrathecal Midazolam also has anti nociceptive effect mediated via spinal opioid receptors. 13

This Randomized controlled trial was conducted to find out the comparative effect of intrathecal Dexmedetomidine and Midazolam as an adjuvant to hyperbaric Bupivacaine in patient undergoing total abdominal hysterectomy. We found that there was prolonged sensory, motor block and postoperative analgesia as compared to Midazolam group. 
Kanazi et al ${ }^{14}$ found that addition of Bupivacaine (12 mg) in spinal anaesthesia with a dosage of Dexmedetomidine (3 $\mu \mathrm{g})$ produced significantly prolonged sensory and motor block than Bupivacaine alone, which is in par with our present study.

Rajni Gupta et al 15 in the study the effect of adding Dexmedetomidine $\mathrm{v} / \mathrm{s}$ fentanyl to intrathecal Bupivacaine concluded that Dexmedetomidine produces more prolonged motor and sensory block as compared with fentanyl. In our present study, Dexmedetomidine group we found prolonged duration of both sensory and motor blockade, stable hemodynamic conditions and good patient's satisfaction. The significant adverse effect was bradycardia and hypotension. In our study hypotension and bradycardia was more in the Dexmedetomidine group than in Midazolam group, but it was not statistically significant.

Shukla et al16 studied the effect of adding Dexmedetomidine v/s Midazolam to hyperbaric Bupivacaine in spinal anaesthesia and found that Dexmedetomidine produced more better motor and sensory block when compared with Midazolam. Time to rescue analgesia was significantly longer in Dexmedetomidine group (380.0 \pm 18.0 $\mathrm{min}$ ) when compared to Midazolam group (220.1 $\pm 14.8 \mathrm{~min})$. We had similar result in our study.

Samantaray et al ${ }^{17}$ studied 60 patients and found time to 2 segment regression and time to $\mathrm{S} 1$ segment regression was significantly longer in Dexmedetomidine group in comparison to Midazolam group. Our study showed us similar results regarding regression time of sensory analgesia.

Choudhary et al.18 in their study showed Dexmedetomidine group had highest incidence of hypotension and bradycardia compared to Midazolam group. Our study had similar results, but it was not statistically significant. Number of patients sedated was more with Dexmedetomidine group than Midazolam group, but it was not statistically significant.

\section{CONCLUSION}

Intrathecal Dexmedetomidine $(10 \mathrm{mcg})$ is more efficient than Midazolam (2.5 mg) as an adjuvant to spinal Bupivacaine for total abdominal hysterectomy. It is associated with longer motor and sensory block and provides excellent quality of post-operative analgesia as compared to Midazolam without any significant hemodynamic instability.

\section{REFERENCES}

[1] Elia N, Culebras X, Mazza C, et al. Clonidine as an adjuvant to intrathecal local anaesthetics for surgery: systematic review of randomized trials. Reg Anaesth Pain Med 2008;33(2):159-67.

[2] Hunt CO, Naulty JS, Bader AM, et al. Perioperative analgesia with subarachnoid fentanyl-bupivacaine for caesarean delivery. Anaesthesiology 1989;71(4):53540.

[3] Al-Ghanem SM, Massad IM, Al-Mustafa MM, et al. Effect of adding Dexmedetomidine versus fentanyl to intrathecal bupivacaine on spinal block characteristics in gynecological procedures: a double blind controlled study. Am J Appl Sci 2009;6(5):882-7.
[4] Al-Mustafa MM, Abu-Halaweh SA, Aloweidi AS, et al. Effect of dexmedetomidine added to spinal bupivacaine for urological procedures. Saudi Med J 2009;30(3):365-70.

[5] Valentine JM, Lyons G, Bellamy MC. The effect of intrathecal midazolam on post-operative pain European Journal of Anaesthesiology 1996;13(6):58993.

[6] Bharti N, Madan R, Mohanty PR, et al. Intrathecal midazolam added to bupivacaine improves the duration and quality of spinal anaesthesia. Acta Anaesthesiol Scand 2003;47(9):1101-5.

[7] Katz J, Melzack R. Measurement of pain. Surg Clin North Am 1999;79(2):231-52.

[8] Kalso E, Poyhia R, Rosenberg PH. Spinal antinociceptin by dexmedetomidine, a highly selective a2-adrenergic agonist. Pharmacol Toxicol 1991;68(2):140-3.

[9] Asano T, Dohi S, Ohta S, et al. Antinociception by epidural and systemic alpha 2 adrenoreceptor agonists and their binding affinity in rat spinal cord and brain. Anesth Analg 2000;90(2):400-7.

[10] Coursin DB, Coursin DB, Maccioli GA. Dexmedetomidine. Current Opinion in Critical Care 2001;7(4):221-6.

[11] Smith MS, Schambra UB, Wilson KH, et al. Alpha 2 adrenergic receptor in human spinal cord: specific localized expression of mRNA encoding alpha-2 adrenergic receptor subtypes at four distinct levels. Brain Res Mol Brain Res 1995;34(1):109-17.

[12] Kanto J, Aaltonen L, Erkkola R, et al. Pharmacokinetics and selective effects of midazolam in connection with caesarean section performance under epidural analgesia. Acta Anaesthesiologica Scandinavia 1984;28(1):116-8.

[13] Faull RL, Villiger JW. Benzodiazepine receptors in the human spinal cord: a detailed anatomical and pharmacological study. Neuroscience 1986;17(3):791802.

[14] Kanazi GE, Aouad MT, Jabbour-Khoury SI, et al. Effect of low dose dexmedetomidine or clonidine on the characteristics of bupivacaine spinal block. Acta Anaesthesiol Scand 2006;50(2):222-7.

[15] Gupta R, Verma R, Bogra J, et al. A comparative study of intrathecal dexmedetomidine and fentanyl as adjuvants to bupivacaine. J Anaesthesiol Clin Pharmacol 2011;27(3):339-43.

[16] Shukla D, Verma A, Agarwal A, et al. Comparative study of intrathecal dexmedetomidine with inhalational magnesium sulfate used as adjuvant to bupivacaine. J Anaesthesiol Clin Pharmacol 2011;27(4):495-9.

[17] Samantaray A, Hemanth N, Gunnampati K, et al. Comparison of the effects of adding dexmedetomidine versus midazolam to intrathecal bupivacaine on postoperative analgesia. Pain Physician 2015;18:71-7.

[18] Choudhary B, Sharma N, Bafna U, et al. Comparison of intrathecal Dexmedetomidine and Midazolam as adjuvants to $0.5 \%$ hyperbaric Bupivacaine for lower abdominal surgeries. Indian Journal of Basic and Applied Medical Research 2018;7(3):225-35. 